\title{
CONFLICTO JURÍDICO DEL RÉGIMEN DE COMERCIO DE EMISIONES DE LA UNIÓN EUROPEA: ESTUDIO DE CASO DE LA INCLUSIÓN DE LAS COMPAÑÍAS AÉREAS POR SU CONTAMINACIÓN Y PERJUICIO AL TURISMO
}

\author{
Autores: F. Javier Heredia Yzquierdo ${ }^{1}$ \\ EAE Business School \\ Antonio Sánchez-Bayón ${ }^{2}$ \\ IsPE-Univ. Camilo José Cela
}

\section{Resumen}

Falta en la actualidad un régimen común de mercado mundial que ordene el control de emisiones contaminantes. Dicha contaminación afecta al relevante

\footnotetext{
${ }^{1}$ Prof. Derecho de Empresa en EAE Business School (EAE). javier.heredia@icam.es

${ }^{2}$ Prof. CC. Sociales y Jurídicas en Univ. Camilo José Cela y coord. académico de TFM en EAE. asbayon@ucjc.edu

Ambos son investigadores del Grupo de Investigación Multidisciplinar en Turismo (GRIT-EAE). Investigación realizada con el apoyo de LAS-Baylor, ELLSP-DePaul, Dpto. Historia Derecho-UNED, EAEInvestigación, GiDECoG-UCJC, IsPE/ISCE, Wizner\&co, CEDEU-URJC
} 
sector del turismo, que se desarrolla en buena medida a través del sector aéreo. Entre los intentos de ordenación de la materia, destaca el modelo de la Unión Europea, pero su regulación unilateral está generando una importante controversia, al oponerse muchos países, en especial las grandes potencias, como los Estados Unidos de América, China e India. Gracias a la polémica suscitada está avanzándose hacia el primer mercado global sectorial, tal como aquí se presenta.

Palabras clave: contaminación; aviación; turismo; mercado de emisiones; Unión Europea; Derecho Comparado y Global.

\title{
Legal conflict on EU GHGS trade system: case study of airline inclusion for its pollution and damage to tourism
}

\begin{abstract}
There is not regulation for a World market to order the GHGs emissions. The aviation industry is a relevant part of the sizable tourism industry. The aviation industry has been growing significantly and become a source of concern for skewing the GHGs policies. The commercial aviation industry is international by its interconnected nature, and it isregulated in an international forum of the United Nations, the ICAO. The ICAO is takin the climate change problem into consideration but not acting in a specific manner. These factors prompted the European Union to incorporate the aviation industry to its ETS. There was a significant international dispute about the matter and currently the situation is on hold. One has to consider if this controversy is also a chance for putting into motion a first World market for a specific sector.
\end{abstract}

Key words: pollution; aviation; tourism; GHG trade; European Union; Global $\&$ Comparative Law.

\section{INTRODUCCIÓN}

Históricamente, las compañías aéreas se habían visto excluidas del mercado de emisión de dióxido de carbono $\left(\mathrm{CO}_{2}\right)$ establecido por el Protocolo de Kioto en 1997. El artículo 2.2 de este Protocolo encomienda a la Organización de Aviación Civil Internacional-OACI (institución especializada de la Organización de las Na- 
ciones Unidas-ONU) el ocuparse de las posibilidades de la regulación del sector de la aviación civil a nivel global en lo que se refiere a un potencial esquema de mercado de derechos de emisión de $\mathrm{CO}_{2}{ }^{3}$.

En la reciente celebración de la Conferencia Internacional sobre el Cambio Climático o COP21 de París (encuentro de representantes de unos 190 Estados, más líderes empresariales, agencias de la ONU, organizaciones no gubernamentales y representantes de la sociedad civil), se llegó a un convenio con el objetivo de asegurar un ambicioso acuerdo jurídicamente vinculante y universal sobre el cambio climático. Aprovechándose la ocasión, se alzaron voces reclamando que la aviación comercial se una al esfuerzo y no se transforme en un bunker ajeno al esfuerzo común: “(...) todos los sectores de la economía global deben reducir sus emisiones de Gases de Efecto Invernadero entre 40-70 $\%$ en comparación con los niveles de 2010. Sin embargo, si no se toman medidas en los sectores de la aviación y el transporte marítimo, se espera que estas emisiones sean "bunkers "cuyas emisiones subirán entre un 50\% y 270\% para el año 2050" (Transportenvironment, 2015). Se ve pues la pertinencia de estudiar dónde nos encontramos en este sector específico y la controversia surgida alrededor de su inclusión en el Régimen de Comercio de Emisiones de la Unión Europea (RCDE-UE).

La citada agencia de la ONU, la OACI, ha venido desarrollando una labor dirigida a minimizar el problema. Se ha llegado a declarar la conveniencia de un sistema de regulación basado en el comercio de derechos de emisión de $\mathrm{CO}_{2}$, afirmándose que "tales medidas podrían lograr objetivos medioambientales a menor coste y de una forma más flexibles"4; en consecuencia, se ha solicitado a los Estados y al Consejo "el desarrollar este asunto como una prioridad el establecer las guías para un comercio de emisiones abierto que se centre en la creación de las bases legales y estructurales para la participación en un sistema de comercio abierto, y que incluya elementos clave tales como el informe, la monitorización y el cumplimiento mientras se provee con la mayor flexibilidad posible dentro del proceso de la Conferencia Mundial de las Naciones Unidas sobre el Cambio Climático"s. Estos esfuerzos no han cesado en el tiempo, tal y como se puede comprobar en las diferentes reuniones y documentos de conclusiones de la institución, aunque las declaraciones de la OACI siguen siendo muy genéricas. Así, en OACI A-36 de 2007, en cuyas

\footnotetext{
${ }^{3}$ Art. 2.2. Protocolo de Kioto-UNFCC (1997): "Las Partes incluidas en el anexo I procurarán limitar o reducir las emisiones de gases de efecto invernadero no controlados por el Protocolo de Montreal generadas por los combustibles del transporte aéreo y marítimo internacional trabajando por conducto de la Organización de Aviación Civil Internacional y la Organización Marítima Internacional respectivamente".

${ }^{4}$ Resolución de la Asamblea OACI A33-7 de 5 de octubre 2001. Apéndice I.

${ }^{5}$ Resolución de la Asamblea OACI A33-7 de 5 de octubre 2001. Apéndice I.c.2.
} 


\section{F. Javier Heredia YzQuierdo y Antonio Sánchez-Bayón}

Resoluciones se plantea el asunto, sin embargo, sólo se pide al Consejo que "continúe estudiando las opciones de política para limitar o reducir el impacto ambiental de las emisiones de los motores de aeronave y desarrollar propuestas concretas y proporcione asesoramiento tan pronto como sea posible a la Conferencia de la Partes de la CMNUCC, que abarca soluciones técnicas y medidas basadas en el mercado"6. Así se entiende que no se haya llegado aún al establecimiento de un funcional mercado transparente y global para el comercio de los derechos de emisión, ni por la OACI, ni por otras organizaciones internacionales afines (e.g. Organización Mundial del Comercio-OMC, Organización de Cooperación y Desarrollo Económico-OCDE). Ahora bien, sí se ha avanzado en las formas para su impulso en las dos últimas Asambleas (A37 de 2010 y A38 de 2013), en las que se ha creado un sistema de comercio basado en medidas basadas en criterios de mercado o Market Based Mechanisms (MBM), cuyo detalle queda pendiente para la próxima Asamblea (A39), a celebrar en el año 2016. Igualmente, se ha creado en el 2014 un grupo de trabajo con ese objetivo (GMTF). Con todo, aún sigue sin establecerse un mercado (como el previsto), siquiera de manera piloto.

Ya desde el año 2005, coincidiendo con la entrada en vigor del Protocolo de Kioto, las políticas de la Unión Europea (UE) han venido mostrando una clara vocación de incluir al sector de las compañías aéreas dentro de sus políticas generales reguladoras de los gases de efecto invernadero. En el año 2006, la Comisión publica un primer borrador de Directiva. Este primer borrador toma en cuenta el trabajo realizado en paralelo por la OACI y lo recoge en su regulación definitiva sobre la cuestión: la Directiva 2008/101/CE de 19 de noviembre de 2008, que modifica la Directiva 2003/87/CE, incluye las actividades de aviación en el $\mathrm{RCDE}$. Con esta regulación, se espera que todas las compañías aéreas reduzcan las emisiones totales de $\mathrm{CO}_{2}$ en los vuelos que aterricen o partan de aeropuertos europeos, aplicando un criterio geográfico.

Cabe resaltar que tal regulación conforme al territorio aeroportuario ha encontrado el apoyo de la mayor organización dentro de la industria del sector del transporte aéreo, la Asociación Internacional de Transporte Aéreo (AITA). En una carta del año 2004, de AITA al Ministro de Asuntos Exteriores austríaco se cita la política de control vía mercado impulsada por la Comisión Europea. Tal fue la controversia que, durante una sesión de preguntas y respuestas respecto al cambio climático y la aviación, se planteó por qué la Comisión había incluido a dicho en el RCDE, y desde la UE se declaró que “(...) En comparación con otras alternativas, como un impuesto sobre el combustible o sobre la del Régimen de Comercio de derechos de Emisiones de la Unión Europea ofrece el mismo beneficio ambiental a un costo menor para la sociedad -o de un mayor benefi-

\footnotetext{
${ }^{6}$ Resolución de la Asamblea OACI A36-22 de 28 de septiembre 2007. Apéndice J, 1, b.
} 
cio ambiental por el mismo costo-. En otras palabras, el impacto en los precios de los billetes, las compañías aéreas y la economía en general serán menores". Continúa el escrito de AITA declarando que "(...) crear nuevos impuestos no es claramente visto como el camino correcto a seguir en la Unión Europea. Este no es el momento de añadir nuevas cargas fiscales a la industria de la aviación" (AITA, 2015). Igualmente, en una entrevista de 2013, Tony Tyler, Director Gral. de AITA, declaró que: "Las líneas aéreas se encuentran comprometidas para trabajar con los Gobiernos con el objetivo de construir una sólida plataforma para un futuro desarrollo sostenible de la aviación. Nos unimos para recomendar a los Gobiernos la adopción de un mecanismo de mercado único para la aviación y ofreceremos sugerencias de cómo se debe aplicar a los operadores individuales. Ahora, la pelota está en el campo de los Gobiernos" (The Guardian, 2013). Desde entonces ha habido más muestras de preferencia por un sistema de control indirecto (de mercado de derechos de emisiones) en detrimento de un control impositivo directo ( command and control).

Cabe preguntarse qué ha despertado el interés de la UE en regular este tráfico, precisamente en el año 2006. Las cifras que se tenían entonces mostraban básicamente el crecimiento exponencial de las emisiones procedentes de las emisiones de $\mathrm{CO}_{2}$. Según algunas fuentes, en ese momento, este crecimiento había llegado ser de un $118 \%$ en los Estados Unidos de América (EE. UU.) entre 1990 y 2006 (EPA, 2011), y de hasta un 80 \% a nivel global en el periodo comprendido entre principios de los años noventa del siglo pasado y el año 2004 (Baker, 2007). En el 2006, se calculaba que los porcentajes de emisión de la industria del transporte aéreo había mostrado un incremento muy superior al de las emisiones globales de combustibles de origen fósil (vid. figura siguiente). El servicio de investigación del Congreso de EE.UU. lo plasmó del siguiente modo: "La aviación ha sido una de las fuentes de crecimiento más importantes del emisiones de CO2 (...) Dentro de la Unión Europea las emisiones provenientes de combustibles fósiles cayeron un $5 \%$ de 1990 a 2009, mientras que las emisiones de combustibles para aviones vendidos en la Unión Europea aumentaron alrededor del $80 \%$. Esto es más el aumento de todas la emisiones de España. De forma global, las emisiones provenientes de la aviación crecieron más rápidamente que todas las emisiones provenientes de combustibles fósiles, a pesar de que la diferencia era menor, la OACI estimó que las emisiones de $\mathrm{CO}_{2}$ de toda la aviación (no solo la internacional) casi se duplicaron de 1990 a 2006. Esto comparado con un incremento del 34\% de todos los combustibles fósiles" (Leggett, et al., 2012). 
Figura 1. Variaciones en emisiones de $\mathrm{CO} 2$ en la aviación internacional y de combustible en UE/mundo

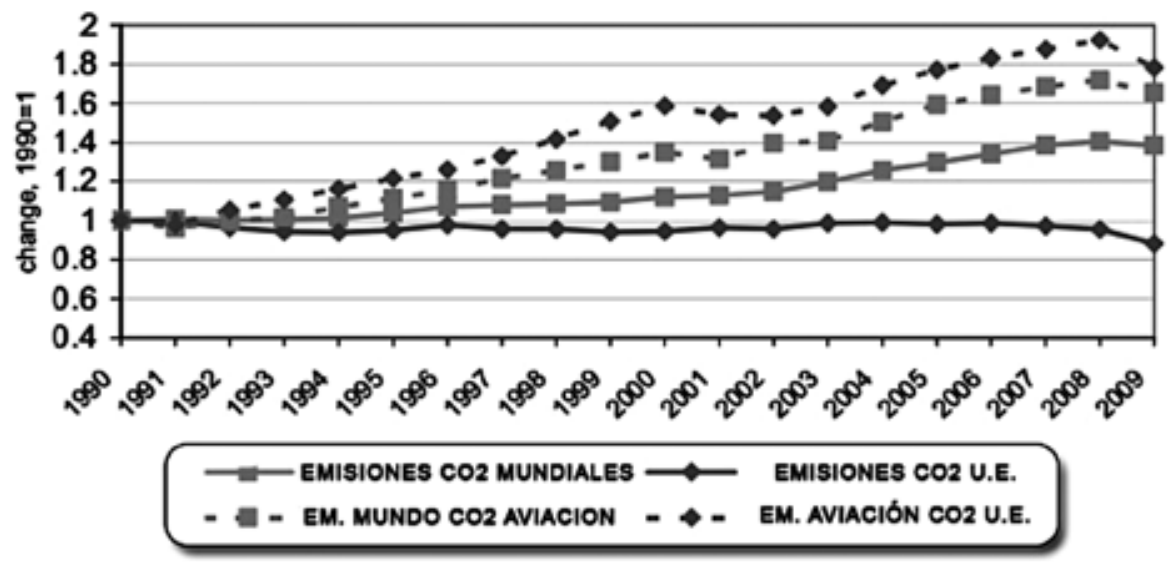

Fuente: elaboración propia (AIE, 1971-2009).

Ahora bien, tal crecimiento es realmente exiguo al lado de lo que se prevé para un futuro no muy lejano. Algunas proyecciones a futuro ponen énfasis en un crecimiento exponencial de estas emisiones. El prestigioso centro Tyndall, para la investigación del cambio climático, ha cifrado un crecimiento de un $667 \%$ hasta el año 2050, si no se toman medidas que puedan mitigar este impacto. Tal previsión provocó reacciones en la Administración de la UE, pensándose en una regulación adecuada, pues resultaba difícil de imaginar que las líneas aéreas llegasen a desarrollar por sí mismas tecnologías que mejoraran el consumo de combustible, reduciéndose la contaminación derivada, en igual proporción que el aumento del tráfico aéreo. Para legitimar las medidas a adoptar, la UE realizó unas previsiones al respecto (sobre la reducción del tráfico de emisiones de $\mathrm{CO}_{2}$ y otros gases de efecto invernadero): para el año 2050 este total debe reducirse en un $80 \%$ y dadas las proyecciones para la industria del transporte aéreo, si no se redujeran las mismas y se produjera el aumento de hasta un $667 \%$ antes mencionado, nos encontraríamos con la paradoja de que solamente este sector emitiría la totalidad del $\mathrm{CO}_{2}$ general para toda los sectores de la UE (Anderson, 2006). En añadidura a los argumento expuestos, el sector del transporte supone entre el 24 y el $28 \%$ de las emisiones de $\mathrm{CO}_{2}$, cuya previsión de crecimiento es: “(...) al igual que el uso de combustible, las emisiones de $\mathrm{CO}_{2}$ provenientes de vehículos se espera que se incrementen en un factor 2.4 (esto es, en un 140\%) (...) en 2050" 
(Fulton, 2004). Además, las emisiones procedentes del sector de la aviación comercial representan el 3,4\% del total de las emisiones de $\mathrm{CO}_{2}$ (Graichen, Gugele, 2006). Este bajo porcentaje no parece ser lo que haya motivado la adopción de medidas por la UE, sino el rápido crecimiento del sector, de ahí la urgencia de una regulación adecuada de contención, de modo que se estimule a las empresas dedicadas a la aviación comercial para que sean capaces de desarrollar tecnologías que mejoren el consumo de combustible y reduzcan la contaminación en la misma proporción en la que crece el mercado: “(...) a pesar del hecho de que hay posibilidades importantes de reducir las emisiones y otros efecto medioambientales, los resultados mostrados por la investigación de la Royal Commission on Environmental Pollution (RCEP, 2002) concluyen que cualquier efecto se verá desbordado por las previsiones de crecimiento del transporte aéreo" (Anderson, et al., 2006).

\section{Figura 2. Previsión de emisiones de $\mathrm{CO} 2$ en vuelos completos EEE}

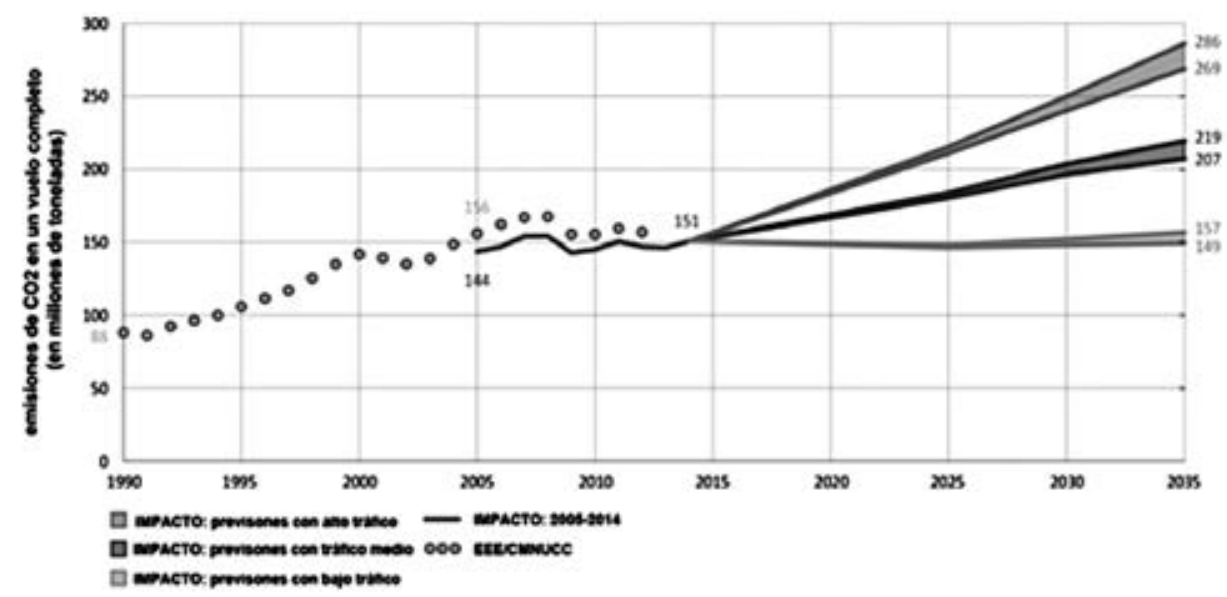

Fuente: elaboración propia (Comisión Europea, 2016).

Igualmente, la propia Comisión Europea recuerda en su último Estudio medioambiental para la Aviación Europea de 2016 que el número de vuelos ha aumentado en un $80 \%$ entre 1990 y 2014, previéndose que crezca en un $45 \%$ adicional entre 2014 y 2035 (Comisión Europea, 2016). En un mismo sentido, en la reconocida revista en el sector, Journal of Sustainable Tourism (JST, 2009), se ha declarado al respecto que: "(...) dentro del sector del transporte, el viaje por vía aérea es de primordial importancia. Primeramente, solo un porcentaje minoritario $(>2 \%)$ del total de la población mundial usa el transporte aéreo 


\section{F. Javier Heredia YzQuierdo y Antonio Sánchez-Bayón}

como forma de transporte internacional (calculo basado en las cifras de la Organización Mundial del Turismo-OMT, 2005). Segundo, las emisiones del viaje por vía aérea es particularmente dañino, ya que son liberadas en la alta troposfera y la baja estratosfera, donde tienen un mayor impacto sobre la nubosidad y la generación de ozono (Sausen, et al., 2005), siendo ambos importantes factores que contribuyen a reforzar la radioactividad y por ende, el calentamiento global. Las emisiones por viaje aéreo se han confirmado como más dañinas para el medioambiente entre 1,9 y 5,1 veces que las emisiones en superficie del tráfico (...) y tercero, el progreso tecnológico en el sector de la aviación es lento" (Gossling, et al., 2009).

Todos estos elementos hicieron que, a pesar del potencial para la controversia, la Comisión Europea tomará la decisión de redactar la Directiva 2008/101/CE de 19 de noviembre de 2008, cuya casuística, efectos y reacciones se analizan a continuación. Ahora bien, antes de proceder a dicho análisis, se llama la atención sobre una consideración preliminar más: afirmar que la aviación aérea comercial había sido insensible a la problemática de las emisiones contaminantes de $\mathrm{CO}_{2}$, no es de recibo, pues el primer marco regulatorio para la industria del transporte aéreo se retrotrae a los años cuarenta del siglo pasado, impulsado por dicha industria. Así, surge el Convenio sobre Aviación Civil Internacional o el Convenio de Chicago, firmado en 1944 (en vigor desde 1947), con el propósito de establecer unas reglas de juego generales con respecto a la aviación internacional, la seguridad y los derechos de los firmantes en relación con el transporte aéreo internacional. La ratificación del Convenio de Chicago supuso la creación de una agencia especializada en el seno de la ONU, la OACI -tal como ya se ha dicho-. Esta agencia agrupa a 191 Estados miembros, coordinados junto con las principales asociaciones del sector. El papel de la OACI resulta de lo más relevante, o al menos así trata de presentarlo la propia organización, que en su Asamblea 36 se declara a sí misma como el organismo responsable de la gestión del problema: “(...) La Asamblea declara que la OACI, como el Agencia de las Naciones Unidas líder en asuntos relacionados con la aviación civil internacional, es consciente de la contaminación aérea y continuará haciendo frente a los impactos ambientales adversos que pueden estar relacionados con la actividad de la aviación civil y reconoce su responsabilidad y la de sus Estados contratantes para lograr la máxima compatibilidad entre el desarrollo seguro y ordenado de la aviación civil y la calidad del medio ambiente" 7 . Dicha autodeclarada responsabilidad de la OACI para conocer del asunto a nivel global se reitera a lo largo de las dos Asambleas

\footnotetext{
${ }^{7}$ Resolución de la Asamblea de OACI, Doc. 9902 (publicado el 28 de septiembre de 2007) Apéndice A. Punto 1 (URL: http://www. OACI.int/environmental-protection/Documents/A36_Res22.pdf; consultado $1 / 1 / 16$, trad. propia).
} 
siguientes, cristalizando en cierta medida en la A38 de Montreal. Tal media es a la que se remiten los actores globales extracomunitarios opositores a la Directiva de la UE, como se expone y explica en el punto referido a la controversia sobre la cuestión.

\section{REGULACIÓN Y CUESTIONES JUDICIALES}

Las cuestiones que se tratan a continuación se enmarcan en seno del RCDE. Este mercado presenta una vertiente de régimen regulado (intervenido e imperativo: hard law) y otra de régimen libre (dispositivo: soft law) (Sánchez-Bayón, 2012 y 2014). Los regímenes regulados emanan de la base jurídica que existe a partir del Protocolo de Kioto, desarrollándose la Convención de las Naciones Unidas para el Cambio Climático (CMNUCC). Se busca siempre facilitar el intercambio del mercado regulado en sus dos vertientes, en los Derechos de emisión o permisos/licencias, y en los Créditos basados en Proyectos.

El régimen de comercio de emisiones queda recogido en el artículo 17 del Protocolo de $\mathrm{Kioto}^{8}$. Y bajo el mismo, los países firmantes del Anexo B del mismo, que coinciden casi en su totalidad con los del Anexo 1 del CMNUCC de 1992 (UNFCCC, 2009), tienen la facultad de efectuar la compra-venta de créditos a través de regímenes de comercio internacional de emisiones. Estos derechos de emisión se conocen por sus siglas en inglés: Assigned Allowance Unit-AAUs.

Por otro lado se contemplan las transacciones basadas en proyectos a través de la llamada Implementación Conjunta o IC (art. 6 del Protocolo de Kioto) ${ }^{9}$ que permite a los países industrializados la adquisición de créditos, denominados Unidades de Reducción de Emisiones (ERUs), cuando financien proyectos de reducción de emisiones en los llamados "países en una economía en transición" que quedan recogidos en el apéndice B del Protocolo de Kioto. La segunda op-

\footnotetext{
${ }^{8}$ Art. 17: La Conferencia de las Partes determinar los principios, modalidades, normas y directrices pertinentes, en particular para la verificación, la presentación de informes y la rendición de cuentas en relación con el comercio de los derechos de emisión. Las Partes incluidas en el anexo B podrán participar en operaciones de comercio de los derechos de emisión a los efectos de cumplir sus compromisos dimanantes del artículo 3. Toda operación de este tipo ser suplementaria a las medidas nacionales que se adopten para cumplir los compromisos cuantificados de limitación y reducción de las emisiones dimanantes de ese artículo.

${ }^{9}$ Art. 6: 1. A los efectos de cumplir los compromisos contraídos en virtud del artículo 3, toda Parte incluida en el anexo I podrá transferir a cualquiera otra de esas Partes, o adquirir de ella, las unidades de reducción de emisiones resultantes de proyectos encaminados a reducir las emisiones antropogénicas por las fuentes o incrementar la absorción antropogénica por los sumideros de los gases de efecto invernadero en cualquier sector de la economía.
} 


\section{F. Javier Heredia YzQuierdo y Antonio Sánchez-Bayón}

ción para las transacciones basadas en proyectos queda recogida en el artículo 12 del Protocolo de Kioto. Son los llamados Mecanismos de Desarrollo Limpio (MDL). Dichos mecanismos ofrecen la posibilidad a los países industrializados de financiar proyectos de reducción de emisiones en países no incluidos en el anexo 1, esto eso, países en vía de desarrollo o no industrializados. Al hacerlo, reciben los llamados Créditos de Reducción Certificada de Emisiones (CERs), que pueden ser empleados para cumplir sus propios objetivos. La implementación conjunta se constituye como independiente de las obligaciones de cumplimiento por parte de los Estados o partes del anexo 1. Su concepción refiere a una visión de mercado según la cual los Estados industrializados ayudarían económicamente a aquellos en vía de desarrollo, y a cambio recibirían derechos de emisión. Los proyectos que entrarían en esa consideración de mercado serían: aquellos tendentes a reducir las emisiones de $\mathrm{CO}_{2}$; de captura de $\mathrm{CO}_{2}$; de apoyo al desarrollo sostenible; y aquellos otros que en general ayuden a ralentizar el calentamiento producido por los gases de efecto invernadero. Preocupada por la creciente influencia del sector, y habida cuenta de que ya existía un mercado regulado, la Comisión Europea decide regular el problema con una Directiva. Con ello se preveía un periodo razonable de armonización dentro de los Estados miembros que afectaría a aquellas compañías aéreas que realizaran su actividad dentro de los aeropuertos de la UE. Así surge la Directiva 2008/101/CE de 19 de noviembre de 2008, que modifica al incluir al sector del transporte comercial aéreo, la Directiva 2003/87/CE. Esta Directiva ha sido complementada y rectificada por legislación posterior: la Decisión 2009/450/CE de 8 de junio de 2009 sobre la interpretación detallada de las actividades de aviación relacionadas en el anexo I de la Directiva 2003/87/CE y más recientemente, por la Decisión n ${ }^{\circ}$ 377/2013/EU del Parlamente Europeo y del Consejo, de 24 de abril de 2013 en la que se establece una excepción temporal a la Directiva 2003/87/CE en relación a la suspensión de las medidas sancionadoras frente a aquellos operadores aéreos que durante el periodo correspondiente al año 2012 no hayan informado sobre las emisiones en las que hayan incurrido en las emisiones de vuelos con origen o destino en países extracomunitarios. Se entiende que en este periodo de tiempo, el RCDE es voluntario -o mejor dicho, dispositivo- para estos vuelos. Sin embargo, con la aprobación del Reglamento n ${ }^{\circ} 421 / 2014$ del Parlamento Europeo y del Consejo, de 16 de abril de 2014 (que modifica igualmente la Directiva 2003/87/CE), se especifican cuestiones que no por ser técnicas son menores, afectándose al régimen de emisiones por las aeronaves. En concreto, se modifica la regulación de los operadores aéreos para adaptarla a la Asamblea 38 de la OACI (A-38) a la que asistieron los 191 Estados miembros y otras organizaciones internacionales invitadas, concluida en octubre 2013 (OACI, 2013). Se efectúan variaciones en la Directiva 2003/87/CE (art. 28 bis y anexo K), por la que quedan excluidos de la aplicación de la misma (desde el 1 de enero de 
2013 hasta el 31 de diciembre de 2020) los vuelos efectuados por operadores no comerciales que emitan menos de mil toneladas de $\mathrm{CO}_{2}$ al año. El objetivo último del cambio de régimen, a instancia de las directrices de la Asamblea de la $\mathrm{OACI}$, era el avanzar hacia un régimen mundial a través de un acuerdo internacional que llegase a aplicar un único sistema de mercado mundial para las emisiones de la aviación internacional. Otra interesante derivación de la Asamblea 38 es la Decisión 377/2013/UE del Parlamento Europeo y del Consejo (de 24 de abril de 2013), por la que se establece una excepción temporal a la Directiva 2003/87/CE, lo que supone la suspensión de las medidas sancionadoras para aquellos operadores aéreos que no informen de las emisiones correspondientes a los vuelos con origen o destino en terceros Estados, ni entreguen derechos relativos a éstas para el año 2012, en el marco del RCDE de la UE. La participación de las compañías en esta propuesta es voluntaria (dispositiva) ${ }^{10}$. Está política, llamada "parada del reloj" (stop the clock) fue la respuesta de la Comisión Europea a la controversia internacional sobre la inclusión de las compañías internacionales aéreas al RCDE, dándose así tiempo a una solución global al problema. El elemento básico de control de las emisiones de $\mathrm{CO}_{2}$ se articula a través de la Directiva 2008/101/CE (de 19 de noviembre de 2008), cuya trasposición a los Ordenamientos internos de cada Estado miembro debía de estar concluida antes del 10 de febrero de 2010 (art. 2) ${ }^{11}$. Esta Directiva introduce nuevo articulado dentro del cuerpo general de la Directiva 2003/87/CE. En concreto, se agrega nuevo texto en los artículos 1, 2, 3, 6, 11, 13, 15, 18, 25 y 30 de la Directiva 2003/87/CE, modificándose además los artículos 14 y 16, y sustituyéndose el artículo 15 de dicha Directiva.

Esto se traduce en las siguientes novedades (Comisión Europea, 2011):

${ }^{10}$ Considerando 6: A fin de facilitar y dinamizar este avance, conviene aplazar la aplicación de los requisitos que hayan surgido con anterioridad al 38 o período de sesiones de la Asamblea de la OACI respecto a los vuelos con origen o destino en aeropuertos situados en países de fuera de la Unión que no sean miembros de la Asociación Europea de Libre Comercio (AELC), en dependencias y territorios de Estados que participan en el Espacio Económico Europeo (EEE) o en países que hayan firmado un Tratado de Adhesión con la Unión. En consecuencia, no deben adoptarse medidas contra los operadores de aeronaves en relación con los requisitos de la Directiva 2003/87/CE del Parlamento Europeo y del Consejo), a efectos de la notificación de las emisiones verificadas respecto de los años civiles 2010, 2011 y 2012, y la correspondiente entrega de derechos de emisión para 2012 relativos a los vuelos con origen o destino en tales aeropuertos. Los operadores de aeronaves que deseen seguir cumpliendo dichos requisitos deben poder hacerlo.

${ }^{11}$ Art. 2 (...) Los Estados miembros pondrán en vigor las disposiciones legales, reglamentarias y administrativas necesarias para dar cumplimiento a lo establecido en la presente Directiva antes del 2 de febrero de 2010. Informarán de ello inmediatamente a la Comisión. Cuando los Estados miembros adopten dichas disposiciones, estas incluirán una referencia a la presente Directiva o irán acompañadas de dicha referencia en su publicación oficial. Los Estados miembros establecerán las modalidades de la mencionada referencia. Los Estados miembros comunicarán a la Comisión el texto de las principales disposiciones de Derecho interno que adopten en el ámbito regulado por la presente Directiva. La Comisión informará de ello a los demás Estados miembros. 


\section{F. Javier Heredia YzQuierdo y Antonio Sánchez-Bayón}

Todos los vuelos que despegan y llegan a los aeropuertos de la UE estarán obligados a cumplir con la Directiva y a controlar las emisiones de CO2 (criterio territorial). Se desprende a sensu contrario que se trata de vuelos de carácter comercial, viendo la definición y excepciones enumeradas en el anexo I de la Directiva. Las excepciones a las Directiva quedan claramente interpretadas a posteriori por la Decisión de la Comisión de 8 de junio de 2009.

Las limitaciones a las emisiones de $\mathrm{CO}_{2}$ es del 97\% del promedio 2004-2006 para los niveles del año 2012 y del $95 \%$ en el periodo $2013-2020$ (art. 3, cap. II).

Los valores de base se han calculado como la media de las emisiones del sector aéreo de los años 2004, 2005 y 2006. Estos valores quedan cuantificados en marzo 2011.

la Comisión Europea su Libro Blanco del Transporte en 221 millones de toneladas de $\mathrm{CO}_{2}$.

Los operadores aéreos tienen que proporcionar emisiones en criterio tonelada/kilómetro con fecha de 2010 para obtener su asignación de derechos de emisión gratuitos. Si sobrepasan esos derechos de emisión gratuitos, deberán compensar el exceso acudiendo al RCDE. Si por el contrario no cubren su cuota, podrán negociar el exceso.

Se utiliza una fórmula para calcular la cuota para cada operador aéreo. Se multiplica el valor de base por los valores tonelada/kilómetro de cada operador en valores año 2010. Cada operador recibe entonces el 85\% (año 2012) o el 83\% (años 2013-2020) en permisos gratuitos.

Se establece una reserva del 3\% del límite de emisiones para casos especiales: operadores que comienzan su actividad después del año 2010 y para aquellos que muestren un incremento superior al $18 \%$ interanual entre el año de referencia y segundo año.

Se asigna a cada operador un Estado miembro de control. El listado de correspondencia operadorEstado se publica anualmente ${ }^{12}$.

El 15\% de los restantes derechos de emisiones (2012) o 17\% (periodo 2013-2020) se concede mediante el método de subasta (art. 3, cap. II). Cuando un operador necesita más derechos de emisión, tiene dos opciones. Puede reducir sus emisiones o puede comprar una asignación a otra parte, ya sea del regulador en la subasta, a otras compañías aéreas, instalaciones o intermediarios o puede comprar Mecanismos de Desarrollo Limpio (MDL) o créditos de implementación conjunta (IC). La Directiva 200/101/CE fue transpuesta en el ordenamiento jurídico interno español a través de la disposición segunda de la Ley 5/2009 de 29 de junio y mediante la Ley 13/2010 de 5 de julio. Esta última ha modificado la Ley $1 / 2005$, de 9 de marzo, reguladora del régimen del comercio de derechos de emisión de gases de efecto invernadero en España.

España sigue las pautas que se indican desde la UE, aunque si bien el interés por estas cuestiones medioambientales son anteriores al ingreso español en la organización (1986). A su vez, España es firmante del Protocolo de Kioto, y parte del Anexo B forma parte de su Derecho interno. Así, en el régimen político-jurídico español sobre derechos de emisiones, se aprecia como primer marco de referencia

${ }^{12}$ Para el año 2009, Reglamento (CE) número 748/2009 de la Comisión de 5 de agosto de 2009. Para el año 2010, Reglamento (CE) número 82/2010 de la Comisión de 28 de enero de 2010. Para el año 2011, Reglamento (CE) número 115/2011 de la Comisión de 2 de febrero de 2011. Para el año 2012, Reglamento (CE) número 100/2012 de la Comisión de 3 de febrero de 2012. Para el año 2013 hay dos Reglamentos. Uno general, el Reglamento (CE) número 109/2013 de la Comisión de 29 de enero de 2013. Y otro posterior que comprende la adhesión de Croacia a la UE, el Reglamento (CE) número 8/5/2013 de la Comisión de 27 de agosto de 2013. En el 2014, el listado de control operador-Estado viene recogido en el Reglamento (CE) número 100/2014 de la Comisión de 5 de febrero de 2014. 
la Estrategia Española de Cambio Climático y Energía Limpia horizonte 2007-20122020, aprobada por el Consejo de Ministros de 2 de noviembre de 2007. Dicha Estrategia (EEDS) aborda diferentes medidas que contribuyen al desarrollo sostenible en el ámbito de cambio climático y energía limpia. La EEDS cuenta como marco de referencia con la "Estrategia Española para el cumplimiento del Protocolo de Kioto" aprobada por el Pleno del Consejo Nacional del Clima el 5 de febrero de 2004. La EEDS debe servir para orientar la capacidad de España a la hora de asumir compromisos adicionales en la lucha contra el cambio climático más allá de 2012. Para el caso que en este artículo ocupa resulta igualmente relevante el destacar la Ley1/2005, que traspone al Ordenamiento interno la Directiva $87 / 2003$, por la que se establece el régimen de comercio de derechos de emisión aplicable a las emisiones de dióxido de carbono procedentes de instalaciones que desarrollan las actividades enumeradas en el anexo I y superen los umbrales de capacidad que en él se establecen. Las asignaciones de dichos derechos se llevan a cabo a través del Plan de Asignación. Los tres Planes Nacionales de Asignación producidos hasta la fecha corresponden a las tres Fases del RCDE de la UE. La legislación a fecha de hoy que sustenta esta parte en el desarrollo de la Fase 3 del RCDE de la UE es el Real Decreto 1722/2012, de 28 de diciembre, por el que se desarrollan aspectos relativos a la asignación de derechos de emisión en el marco de la Ley $1 / 2005$, de 9 de marzo, por la que se regula el régimen del comercio de derechos de emisión de gases de efecto invernadero. Finalmente, la Directiva 2008/101/CE fue transpuesta al Ordenamiento jurídico español a través de la disposición segunda de la Ley 5/2009 de 29 de junio, y mediante la Ley 13/2010 de 5 de julio. Esta última ha modificado la Ley 1/2005, de 9 de marzo, reguladora del régimen del comercio de derechos de emisión de gases de efecto invernadero en España. En última instancia, es cada Estado controlador quien otorga los derechos a los operadores aéreos cuyo control es de su competencia. El listado con los valores queda asignado anualmente para cada compañía. En el caso de España, la Secretaría de Estado de Medio Ambiente, a través de la Oficina española para el cambio climático, es quien publica la propuesta de ese listado (Magrama, 2011).

\section{EFECTOS DE LA REGULACIÓN}

Los principales efectos de la regulación que se viene exponiendo, tocante a los distintos operadores aéreos comerciales, se cifra en los sobrecostes que esta inclusión en el mercado puede tener, si realmente es un sistema efectivo para el control de las emisiones de $\mathrm{CO}_{2}$, y por último, las penalizaciones que pueden sufrir las distintas compañías comerciales aéreas. El impacto de incluir los costes por la adquisición de derechos de emisión de $\mathrm{CO}_{2}$ se produce a través de distintos canales. Puede tener un doble efecto: la mejora de la eficiencia o una subida en el 


\section{F. Javier Heredia Yzquierdo y Antonio Sánchez-Bayón}

precio de los billetes, que puede afectar a la demanda de los mismos. Sin embargo, y como enuncia la ICTDS en su informe: “(...) en la industria de la aviación, la eficiencia en el combustible es una medida común, ya que los costos por combustible suponen unos de los mayores costes en el funcionamiento de una aerolínea. Las medidas incluyen la instalación de dispositivos de punta alar, la reducción de peso, la renovación en la flota y la optimización de las rutas de vuelo, entre otros" (Faber, et al., 2011).

Otros estudios afirman que los precios de los combustibles son muy volátiles. De hecho, en los últimos meses los precios del petróleo no han hecho más que descender, muy notablemente en el último año (se observa una diferencia de precio de un -40,33\% entre marzo 2015 y febrero 2016). Esto queda reflejado en la siguiente figura.

Figura 3. Precios de combustibles para jets (precio FOB-USD)

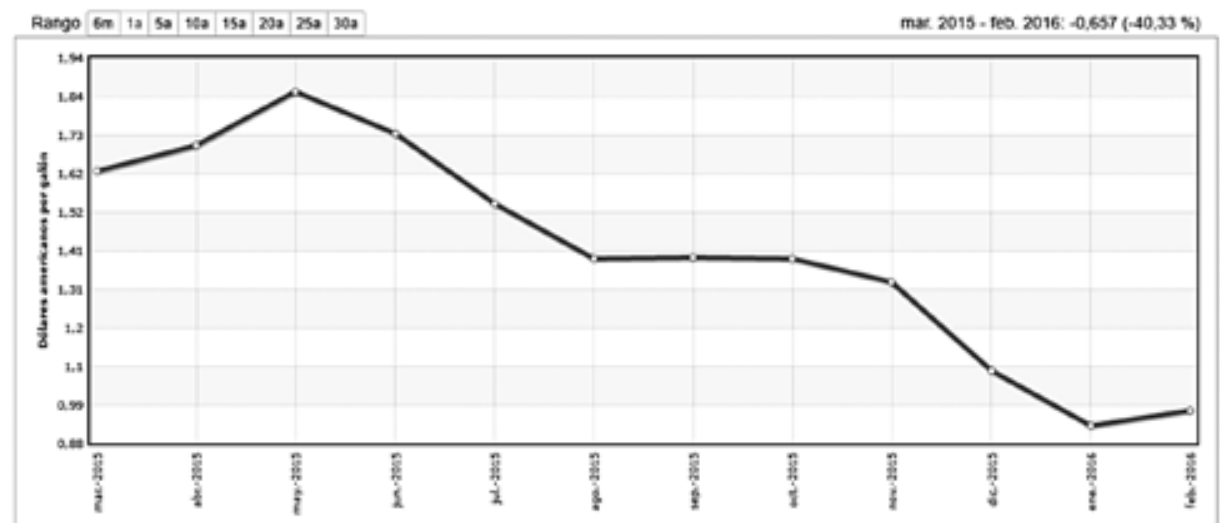

Fuente: Indexmundi, 2016.

Los precios han bajado a nivel mundial y permanecen bajos en los últimos meses, con un precio medio por galón inferior a los 0,99 dólares estadounidenses (Indexmundi, 2016). Otro factor a calibrar es el impacto en cuanto al control mismo de las emisiones. Este es el objetivo último desde el punto de vista del medioambiente, no lo es la obtención de recursos económicos extraordinarios por parte del regulador, esto es solo un medio para este fin. Se puede entrar a considerar a partir de qué precio esta medida resulta exitosa para la obtención de este fin. Un reciente estudio de CEDelf explica que con los precios actuales, les resulta más barato a los operadores aéreos asumir el sobrecoste de la obtención de derechos de emisiones de otros sectores que tener que implementar medidas para reducir sus propias emisiones (Faber, et al., 2011). 


\section{REACCIONES INTERNACIONALES}

\subsection{Situación en la UE}

Al buscar la UE una forma de reducir las emisiones de $\mathrm{CO}_{2}$ a través de involucrar a la industria comercial aérea $\mathrm{CO}_{2}$ para los vuelos que operan en el espacio aéreo de la UE en el mercado obligatorio de derechos de emisiones de $\mathrm{CO}_{2}$ se ha producido una situación con repercusiones de ámbito internacional extracomunitario. Sirva como ejemplo, un vuelo Madrid-Tokio operado por JAL, operador extracomunitario, deberá cubrir todas las emisiones de $\mathrm{CO}_{2}$ del mismo, esto es, las que se produzcan no solo en el espacio aéreo de la UE sino también las que se produzcan en terceros países, alta mar y el espacio aéreo japonés. La controversia está servida, ya que se trata de delimitar el auténtico límite jurisdiccional en el comercio y el transporte aéreo de la UE.

El debate se ha producido, como es en cierta medida lógico en el mundo multipolar del siglo XXI, con los otros grandes bloques comerciales. Así, EE. UU., China e India han manifestado su disconformidad con el sistema unilateral europeo.

Por otro lado, es conveniente considerar la existencia de la política de espacios aéreos libres que se concretó en el Acuerdo de Cielos Abiertos realizado entre la UE y EE. UU. El Acuerdo de Transporte Aéreo, firmado el 25 y 30 de abril de 2007, aplicándose provisionalmente desde el 30 de marzo de 2008 para todos los Estados miembros. El 24 de junio de 2010 se enmienda vía un Protocolo, de modo que Noruega e Islandia se unen al mismo a partir del 21 de junio del año 2011. El Acuerdo tiene "el objetivo último de la Unión Europea es la creación de un espacio aéreo abierto transatlántico: un mercado único del transporte aéreo entre la UE y los EE. UU. con libre flujo de la inversión y no hay restricciones en los servicios aéreos, incluyendo el acceso a los mercados nacionales de ambos partidos" (Comisión Europea, 2011). Este Acuerdo será recordado ampliamente en la posterior polémica generada por la Directiva.

Los EE. UU., fue el Estado que antes reaccionó frente a la Directiva. La Asociación para el Transporte Aéreo de América (ATAA), junto con las aerolíneas más relevantes del país, recurrieron al Reino Unido de Gran Bretaña (UK) como plataforma jurídica desde donde litigar contra la Directiva ${ }^{13}$. Tal elección vino motivada porque: a) UK había sido el primer Estado de la UE en incorporar la Directiva a su Ordenamiento interno en 2009; b) la cercanía del Derecho británico al estadounidense, por ser ambos Ordenamientos de la familia jurídica de Derecho Común Anglosajón (Sánchez-Bayón 2011 y 2012). Sin embargo, el caso se derivó por parte de Alto Tribunal de Justicia de Inglaterra y Gales a las instancias europeas, ya que sólo el Tribunal de Justicia de la Unión Europea (TJUE) tiene la potestad de declarar inválida la regulación emanada de la UE. El caso levantó gran polémica, y el 6 de octubre de 2011 la Abogada General del TJUE, Julianne

\footnotetext{
${ }^{13}$ Caso C-366/10 ATA, URL: http://ec.europa.eu/dgs/legal_service/arrets/10c366_en.pdf
} 
Kokott, estableció que el Derecho de la UE resultaba compatible con los acuerdos internacionales relevantes que se reclamaban en el caso (TJUE, 2011).

\subsection{Comentarios a la resolución del Tribunal de Justicia de la Unión Europea (TJUE)}

Los demandantes (del citado caso) fueron tres compañías aéreas estadounidenses (en concreto, American Airlines Inc., Continental Airlines Inc, y United Airlines Inc.), llamadas en la sentencia como "las compañías", junto con ATAA. Dichos demandantes plantearon la cuestión, presentándola contra la Secretaría de Estado para la Energía y el Cambio Climático de UK (el demandado), ante el Alto Tribunal de Justicia de Inglaterra y Gales, que lo refiere en mayo de $2010 \mathrm{al}$ TJUE, para que sea este quien resuelva como una cuestión prejudicial.

Se trata de un caso complejo, en el que también se presentan como partes la propia OACI, el Consejo nacional de Canadá de líneas aéreas (NACC, en sus siglas en inglés), la Federación para el medioambiente en la Aviación, la Federación Europea para el Transporte y el Medioambiente, el Fondo de Defensa del Medioambiente, y la organización Earthjustice.

Los demandantes alegaron que la inclusión de las compañías comerciales aéreas en el programa de mercado de derechos de emisión de UE vulneraba acuerdos y regulación internacional. Se centró la demanda en la violación del Protocolo de Kioto, del Acuerdo de Cielos Abiertos de 2007 entre EE. UU. y la UE y la Convención de Chicago. Además, se entendió que la Directiva excedía la jurisdicción de la UE, y que en realidad la inclusión en el RCDE no era sino un arancel o un impuesto encubierto. El Tribunal consideró igualmente la defensa del Gobierno de UK, en la que se alegaba que la Directiva contestada se debía interpretar como una medida de incentivo internacional para motivar a otros Estados a tomar disposiciones similares, siendo compatible con los acuerdos internacionales vigentes. Fue el 6 de octubre de 2011 cuando uno de los ocho Abogados Generales, la Doctora Juliane Kokott, validó la Directiva ${ }^{14}$. Aunque la opinión del Abogado General no es vinculante, si es parte ineludible del proceso de una cuestión prejudicial ante el TJUE, y suele ser tenida extremadamente en cuenta por el mismo. En la opinión del Abogado General Doctora Kokott, no se encontraron elementos susceptibles de invalidar la Directiva 2003/87/CE, modificada por la Directiva 2008/101/CE.

${ }^{14}$ Art. 252, del Tratado de Funcionamiento de la Unión Europea: “(...) El Tribunal de Justicia estará asistido por ocho abogados generales. Si el Tribunal de Justicia lo solicitare, el Consejo, por unanimidad, podrá aumentar el número de abogados generales. La función del Abogado General consistirá en presentar públicamente, con toda imparcialidad e independencia, conclusiones motivadas sobre los asuntos que, de conformidad con el Estatuto del Tribunal de Justicia, requieran su intervención" (URL: http:// www.seap.minhap.gob.es/dms/es/publicaciones/centro_de_publicaciones_de_la_sgt/Monografias0/parrafo/0111113/text_es_files/TUE-TFUE-castellano-INTERNET.pdf página 88; consultado 1/1/16). 
La Abogada General, la Dra. Kokott, encuentra que la UE no es parte firmante de la Convención de Chicago, ya que ésta fue firmada por los distintos Estados que comprenden la UE, pero no por la propia institución -por carecer de capacidad jurídica hasta 2007-. También recuerda que los entonces 27 Estados miembros pertenecen a la $\mathrm{OACI}$, pero que la UE solo tiene carácter de observador en la misma, por lo que no procede contemplar la validez de la Directiva cuestionada a la luz de dicha Convención. El hecho de que la UE no haya firmado dicha Convención motiva en sus propias palabras, que no pueda ser sujeto ni estar obligada por la misma: "El principio general - reconocido también bajo el derecho internacional - del efecto relativo de los tratados se aplica, según el cual los tratados no confieren derechos ni imponen obligaciones a terceros Estados "pacta tertiis nec nocent nec prosunt"15.

En lo referente al Protocolo de Kioto, la Abogada General admitió que efectivamente el mismo fue ratificado tanto por los 27 miembros de la UE en 2011 como por la Comunidad Europea, subrogada a partir del Tratado de Lisboa por la UE (2007). Sin embargo, encuentra apoyo legal en el propio Tratado para las medidas adoptadas por la Directiva cuestionada. Así, se cita el art. 2.1.a.vii del Protocolo que permite a las partes tomar "medidas para limitar y/o reducir las emisiones de gases de efecto invernadero no controlados por el Protocolo de Montreal en el sector del transporte" y recuerda que el mismo Tratado hace alusión explícita al sector de la aviación en su art. 2.216. Se afirma igualmente que el Protocolo de Kioto es un tratado general que no tiene consecuencias específicas para los individuos, por lo que no puede ser utilizado para reclamaciones legales individuales, como las de las líneas aéreas. El Abogado General afirma que “(...) todos los compromisos del Protocolo de Kioto han de ser transpuestos a la ley nacional, y, por consecuencia, no son los suficientemente precisos para ser capaces de tener un efecto directo beneficial o adverso en individuos"17.

Si bien el Protocolo de Kioto no parece poder ser reclamado por partes individuales, la Abogada General sí es de la opinión de que los individuos pueden reclamar en base al Acuerdo de Cielos Abiertos. En este caso, se admite que el propio tratado da entrada al concepto de individuo: "Con todo, por lo tanto, soy de la opinión que el Acuerdo de Cielos Abiertos por su propia naturaleza y lógica en un sentido amplio, afecta al estado legal de los individuos. En procedimientos jurídicos el Acuerdo de Cielos Abiertos puede por tanto ser utilizado en principio como punto

${ }^{15}$ Opinión de la Abogada General Kokott, de 6 octubre 2011. Caso C-366/10-The Air Transport Association of America and Others -(Reference for a preliminary ruling from the High Court of Justice of England and Wales, Queen's Bench Division, Administrative Court-UK), p. 23 y 24, (URL: http://ec.europa.eu/clima/news/docs/2011100601_case_c366_10_en.pdf; consultado 1/1/16; traducción propia).

${ }^{16}$ Opinión de la Abogada General Kokott... op. cit., p. 8.

${ }^{17}$ Opinión de la Abogada General Kokott... op. cit., p. 30. 


\section{F. Javier Heredia YzQuierdo y Antonio Sánchez-Bayón}

de referencia contra el cual se pueden revisar los actos de la Unión Europea" ${ }^{18}$ Por tanto, acepta que se reclame bajo ese Acuerdo, aunque reduce su impacto solo a lo referido a los artículos 7 (sobre la aplicación de la normativa) ${ }^{19}$ y 15.3. (sobre el medioambiente ${ }^{20}$ del mismo en su conclusión provisional, por lo que habrá que contrastar la validez de la Directiva 2008/101 en lo que respecta al principio de territorialidad. Sobre este punto, el Abogado General opina que "La Unión Europea puede invocar el principio de territorialidad en el caso presente (...) El despegue y el aterrizaje son elementos esenciales y particularmente característicos de cada vuelo. Si el lugar de partida o de destino es un aeródromo dentro del territorio de la UE se dará un vínculo territorial adecuada para que el vuelo en cuestión que sea incluido en el régimen de comercio de emisiones de la UE"21. Como suele pasar, la decisión del caso C-366/10, publicado el 21 de diciembre de 2011, sigue las directrices de la opinión de la Abogada General. Concluyendo en su decisión final en los siguientes términos: “(...) el examen de la Directiva 2008/101 no ha puesto de manifiesto elementos que puedan afectar a su validez"22. Así pues, no había impedimentos por parte de los órganos judiciales supremos europeos para que la Directiva desplegara sus efectos.

Eso motivó una respuesta casi inmediata por parte de EE. UU. a finales del año 2011. Así, encontramos que la Secretaria de Estado Hillary Clinton y el Secretario de Transporte Raymond H. LaHood han declarado que "se oponen fuertemente por motivos legales y políticos" a la aplicación de la Directiva de Aviación a las compañías aéreas estadounidenses e instó a la UE a detener, suspender o retrasar

\footnotetext{
${ }^{18}$ Opinión de la Abogada General Kokott... op. cit., p. 34.

${ }^{19}$ Decisión del Consejo y de los representantes de los Gobiernos de los Estados Miembros de la UE, reunidos en el seno del Consejo (de 25 de abril de 2007), relativa a la firma y la aplicación provisional del Acuerdo de transporte aéreo entre la Comunidad Europea y sus Estados miembros, por una parte, y los Estados Unidos de América, por otra (2007/339/CE): "Artículo 7. Aplicación de la normativa.1. Las leyes y reglamentaciones de una Parte relativas a la entrada en su territorio o salida del mismo de aeronaves dedicadas a la navegación aérea internacional, así como a la operación y navegación de dichas aeronaves en el interior del territorio de esa Parte, se aplicarán a las aeronaves utilizadas por las líneas aéreas de la otra Parte, las cuales cumplirán dichas leyes y reglamentaciones cuando entren en el territorio de una Parte o salgan del mismo, y mientras permanezcan en él."

${ }^{20}$ Decisión del Consejo y de los representantes de los Gobiernos de los Estados Miembros de la UE, reunidos en el seno del Consejo de 25 de abril de 2007, relativa a la firma y la aplicación provisional del Acuerdo de transporte aéreo entre la Comunidad Europea y sus Estados miembros, por una parte, y los Estados Unidos de América, por otra (2007/339/CE): "Artículo 15. Medio ambiente 3. Cuando se establezcan medidas ambientales se observarán las normas aprobadas por la Organización de Aviación Civil Internacional en los anexos al Convenio, excepto si se han notificado diferencias. Las Partes aplicarán cualesquiera medidas ambientales que afecten a los servicios aéreos amparados por el presente Acuerdo, de conformidad con el artículo 2 y el artículo 3, apartado 4, del presente Acuerdo" (traducción propia).

${ }^{21}$ Opinión de la Abogada General Kokott... op. cit., p. 48.

${ }^{22}$ Sentencia del Tribunal de Justicia (Gran Sala), de 21 de diciembre de 2011 (URL: http://curia. europa.eu/juris/document/document.jsf?text $=\&$ docid $=117193 \&$ pageIndex $=0 \&$ doclang $=$ es $\&$ mode $=$ req $\&$ dir $=\& o c c=$ first $\&$ part $=1 \&$ cid $=246866$; consultado $1 / 1 / 16$ ).
} 
la aplicación de la Directiva en su carta a la Comisión Europea de 16 de diciembre de 2011, al tiempo que se “(...) urge a la Unión Europea y a sus Estados Miembros dentro de sus respectivas competencias a volver a trabajar con, y no contra la Comunidad Internacional, en el foro multilateral apropiado, la OACI, para afrontar el importante desafío de la reducción de emisiones en el sector aéreo". En esta carta se incluye, además, un listado provisional de naciones opuestas a la medida $^{23}$. Muy poco antes, el 24 de octubre de 2011, la Cámara de Representantes de EE. UU. aprobó un proyecto de ley que haría ilegal para las compañías aéreas de los EE. UU. cumplir con la Directiva de la UE. En la misma, en un tono poco diplomático, pero que despliega efectos legales poco concretos, se llega a enunciar que "(...) no hay seguridad de que los ingresos provenientes del RCDE será usado con los propósitos medioambientales de la aviación por parte de los Estados miembros de la Unión Europea que los recauden" (sección 2, punto seis) y en la misma, se prevé que el secretario de transporte norteamericano "(...) prohibirá a un operador de una nave aérea de los Estados Unidos participar en cualquier sistema de comercio de emisiones establecido unilateralmente por la Unión Europea" (sección 3) 24 . Este proyecto de Ley es firmado por el Presidente Obama y se convierte en Ley Pública (Public Law -equivalente a una ley orgánica española-) del 27 de noviembre de 2012 25 . Una Ley de articulado exiguo, en el que de forma general se otorga al Secretario de Transporte de EE. UU. la potestad de prohibir a los operadores aéreos estadounidenses el participar el mercado de emisiones de la UE al considerarlo unilateral. El marco normativo es muy vago en lo que se refiere a auténticas penalizaciones específicas para quien lo vulnerara, pero otorga un marco general que permitiría desarrollar el detalle de esta norma ${ }^{26}$. Esta legislación no suponía un marco jurídico concreto con regulación específica ni punitiva para aquellas compañías aéreas comerciales estadounidenses que decidieran incluirse en el RCDE. Tampoco se ha involucrado a la OMC en la controversia hasta la fecha. Pero ya en ese momento, principios de 2012, la Comisión cobra plena consciencia de hasta qué punto va a ser fuerte la oposición internacional a su Directiva.

${ }^{23}$ Carta de la Secretaria de Estado Hillary Clinton y el Secretario de Transporte de Raymond H. LaHood, de 16 de diciembre de 2011 (URL: http://www.nbaa.org/ops/environment/eu-ets/20111216-euets-us-state-department-4clinton.pdf; consultado 1/1/16, traducción propia).

${ }^{24}$ Trabajos preparatorios del proyecto de ley estadounidense (vid. supra ley final, URL: https://www. govtrack.us/congress/bills/112/hr2594/text; consultado 1/1/16, traducción propia).

${ }^{25}$ Public Law núm. 112-200 (URL: https://www.congress.gov/bill/112th-congress/senate-bill/1956/ text https://www.congress.gov/112/bills/s1956/BILLS-112s1956enr.pdf; consultado 1/1/16, traducción propia).

${ }^{26}$ Sec. 2. Prohibición de participación en el régimen de comercio de emisiones de la UE. (a) EN GENERAL.- El Secretario de Transporte prohibirá a cualquier operador de una aeronave civil de los Estados Unidos el participar en el régimen de comercio de emisiones establecido unilateralmente por la Unión Europea en la Directiva de la UE 2003/87/CE de 13 de octubre de 2003, en su versión modificada (traducción propia). 


\section{F. Javier Heredia Yzquierdo y Antonio Sánchez-Bayón}

Por otro lado, la República Popular China (China) ha afirmado que la inclusión de sus compañías aéreas en el Régimen de Comercio de Emisiones de la UE viola la Convención Marco de las Naciones Unidas sobre el Cambio climático (CMNUCC) al vulnerar el principio de responsabilidad común pero diferenciada (BCRD). Este principio enuncia la idea de que no se deben esperar un nivel de esfuerzo similar entre los países desarrollados y los países en vías de desarrollo a la hora de reducir sus emisiones de $\mathrm{CO}_{2}$ y que esta inclusión también vulneraría igualmente la Convención Internacional sobre Aviación Civil la cual adoptó una declaración oponiéndose a aquellas partes de la Directiva sobre la Aviación de la UE que obliga a las compañías aéreas de terceros países a comprar derechos de emisión. ${ }^{27}$ Según sus cálculos, la inclusión de las compañías aéreas chinas en el RCDE les supondría un coste de 2.400 millones de yuanes en el año 2020, algo inasumible en un país que no es parte del apéndice 1 del Protocolo de Kioto (Leung, 2012). La presión china se acentúa y no solo de forma unilateral. Por una lado, firma junto a la Federación Rusa una declaración conjunta el 7 de julio de 2011 sobre la "inclusión de actividades aéreas en el sistema de mercado de derechos de emisiones de la Unión Europea" condenando la misma y no excluyendo la posibilidad de llevar a cabo medidas de presión al respecto. Así mismo, contempla la toma de medidas adicionales, tales como compensaciones fiscales a las líneas aéreas chinas afectadas o incluso poniendo en duda la compra de aviones procedentes de la industria europea, los Airbus 330 y 380, en favor de sus competidores de Boeing (Verki, 2012).

La India también protestó ante esta medida unilateral por parte de la UE. El Ministro de Medioambiente indio Natarjan escribió una carta de aviso a entonces Comisaria de Medioambiente, Connie Hedegaard el 28 de diciembre de 2011, en la que avisaba que "enérgicamente insto a la UE a reconsiderar y revertir la decisión de aplicar el Régimen de Comercio de Emisiones de la Unión Europea a las compañías aéreas no-UE (...) La India está convencida de que una medida unilateral como la que se propone adoptar la Unión Europea, se destaca no sólo en la violación de los Principios y Disposiciones de la Convención (internacional para el cambio climático ), sino que no será un buen augurio para el éxito de las futuras negociaciones sobre el cambio climático" (UPI, 2012).

\subsection{La situación actual}

En este contexto de controversia internacional legal y con el cumplimiento de la primera fase de inclusión a punto de realizarse la Comisión decidió de forma un tanto sorprendente en noviembre de 2012 suspender provisionalmente la inclusión de la aviación internacional en el mercado de emisiones. Esta suspensión era breve,

${ }^{27}$ Statement by the China Air Transport Association (CATA) on the EU ETS, de 10 de marzo de 2011 (URL: http://www.wcarn.com/cache/news/13/13140.html; consultado 1/1/16, traducción propia). 
de tan solo un año: no suponía una exclusión durante ese periodo de tiempo, ya que terminado el mismo, se vuelve a "poner en marcha el reloj" del programa de inclusión, que sigue incluyendo al año 2012 y la fase del 2013-2020. Tampoco era un criterio para todos los vuelos, ya que todos los vuelos dentro del Espacio de la UE no se encontraban bajo los efectos de "parada del reloj". El propósito declarado de la decisión de "parada del reloj " era dar oportunidad a la OACI para tratar de negociar un acuerdo global frente a las emisiones de la aviación internacional en la reunión de la Asamblea de la OACI en septiembre-octubre de 2013, en Montreal, Canadá.

Allí, el cuatro de octubre, la OACI concluyó dos semanas de negociaciones en las que se acuerda desarrollar un sistema global en base a un modelo de mercado de derechos de emisiones. Este sistema se denominó MBM, y sigue las líneas que la OACI ya había adelantado en 2011 (OACI, 2011). Este acuerdo hizo así mismo un llamamiento para que estas medidas se pudieran acordar finalmente en la próxima Asamblea de 2016 con el objetivo de que el Sistema se pudiera implementar en el año 2020. Esto, es, no se llegó a ningún acuerdo vinculante y se pospuso la decisión al 2016 (OACI, 2013). El propio texto del acuerdo de la Asamblea 38 de la OACI de Montreal lo recoge explícitamente al afirmar "Recordando la Resolución A37-19 de la Asamblea en virtud de la cual se pedía al Consejo que, con el apoyo de los Estados miembros, emprendiera la labor de determinar un marco para las medidas basadas en el mercado $(\mathrm{MBM})$ para la aviación internacional, incluida una explicación más a fondo de los principios rectores que se enumeran en el Anexo, para someterlo a la consideración del $38^{\circ}$ período de sesiones de la Asamblea de la OACI (... 9. 9.- Acepta examinar, en su $39^{\circ}$ período de sesiones, la meta mencionada en el párrafo 7 en vista de los avances que se hayan hecho hacia su concreción, los estudios con respecto a la viabilidad de alcanzar la meta y la información pertinente de los Estados"28.

La respuesta de la Comisión fue la de publicar en octubre de 2013 una propuesta, que se esperaba que tomara la forma de Directiva, que adoptará el concepto de "espacio soberano". Esto supone de facto desechar las resoluciones de las Asamblea de la IACI antes mencionada, ya que esta Asamblea rechazó este concepto. Sin embargo, esta iniciativa ve la luz como Reglamento, el Reglamento (UE) N 421/2014 del Parlamento Europeo y del Consejo. La aproximación final a la Comisión al asunto puede calificarse como moderada. Con esta regulación básicamente se extiende la política de "parar el reloj" para el periodo 2013-2016. El reglamento también exime de su inclusión en el mercado de compraventa de derechos de $\mathrm{CO}_{2}$ a ciertos vuelos entre "regiones ultra periféricas" de la UE para el periodo 2013-2016. Más aún, en relación a la norma de cumplimiento de mínimos, se concede una excepción a la exención de inclusión en el régimen de mercado de compraventa de derechos de emisiones para aquellos operadores de

\footnotetext{
${ }^{28}$ Asamblea OACI 38. Resoluciones adoptadas por la Asamblea. Noviembre 2013. A38-18 (URL: http://www. OACI.int/Meetings/a38/Documents/Resolutions/a38_res_prov_es.pdf, p. 102 y 105; consultado $1 / 1 / 16$, trad. propia).
} 


\section{F. Javier Heredia Yzquierdo y Antonio Sánchez-Bayón}

aeronaves que emitan menos de un total de 1.000 toneladas de $\mathrm{CO}_{2}$ al año, para el periodo comprendido entre 2013 y 2020. Las fechas para informar sobre las emisiones y derechos de emisión consumidos del año 2013 se han extendido a marzo y abril de 2015 para que coincidan con las del año 2014. Es importante remarcar que la regulación no extiende el deber de compraventa de derechos de emisión para la parte proporcional dentro de espacio aéreo del EEE para aquello vuelos efectuados entre aeropuertos de Estados miembro de la EEE y terceros países. Es clara la voluntad de la Comisión Europea en mantener viva la de la industria de la aviación en el sistema europea de mercado de derechos de $\mathrm{CO}_{2}$, pero a un nivel práctico se está buscando un enfoque suave dado que el nivel de controversia internacional sigue siendo alto. Así que por el momento la industria de la aviación sólo tiene que considerar la opción de la compraventa de derechos de emisiones para vuelos internos dentro de la UE. Esta realidad se ver refrendada por la posición de las tres mayores economías de la UE, que no están haciendo cumplir las sanciones. Los medios de comunicación especializados del sector de la aviación han tomado buena nota de ello "Francia, Reino Unido y Alemania no van a hacer cumplir las sanciones en caso de incumplimiento" (Airportwatch, 2014).

\section{EL CASO "HUSH KIT"}

Las reglas del Derecho comparado invitan a la analogía, para salvar el horro vacui o laguna jurídica, como supone la controversia que se viene tratando (SánchezBayón, 2011, 12 y 14). Para ello se recurre a la exposición y explicación de la resolución de una controversia anterior similar entre la Comisión Europea, otros actores relevantes y la OACI: se refiere al caso de contaminación acústica "Hush Kit".

El ruido de los aviones es un tema especialmente sensible para la UE ya que los aeropuertos de la UE están a menudo en zonas de población muy densa y existe una fuerte presión pública para que se haga frente a este problema ambiental. Una vez más, el lento progreso de la OACI sobre la cuestión de las medidas de control de ruido de aeronaves, hizo que la UE adoptara medidas de control de ruido más estrictas que las aprobadas por la OACI. El caso es el siguiente: Las normas de la OACI para el ruido se basan en el Anexo 16 del Convenio sobre aviación civil internacional, cuya versión en vigor en el momento de la controversia era la tercera edición de julio 1993. Para ser certificado como un avión del Capítulo 3, una aeronave debe tener un motor que produce un ruido mínimo. Las normas para el ruido permitido para el control de motores para aviones del Capítulo 2 de la OACI permitían los motores técnicamente modificados con Hush-Kits o equipos de silenciamiento, que actuaban como un silenciador para reducir el ruido. Estos aviones podría entonces ser recalificados como aviones que cumplen con las normas del capítulo 3 de aeronaves en relación con el ruido, tal y como explica Reglamento (CE) Nº 925/1999 
del Consejo de 29 de abril de 1999 o Reglamento Hush-Kit en su Punto 5. El Reglamento Hush-Kit de la UE proponía prohibir que aeronaves modificadas en el espacio aéreo de la UE, que sólo permita aviones que habían sido certificadas originalmente como conformes con el Capítulo 3 de ruido. La UE sostuvo que una aeronave modificada Capítulo 2 era aún más ruidosa que una aeronave del Capítulo 3, causando igualmente más contaminación del aire y mayor consumo de combustible.

El Reglamento Hush-Kit fue muy criticado los EE. UU., ya que el uso de dispositivo Hush-Kit era muy corriente entre las aerolíneas estadounidenses, mientras que apenas se daba en aviones de la UE. Se interpretó desde EE. UU. como una medida proteccionista usando un pretexto medioambiental. El Gobierno de EE. UU. se puso del lado de la industria aeroespacial con base en EE. UU. y en particular con los productores locales de motores Hush-Kit (Knorr, Arndt, 2002).

Esta controversia llevó a la OACI a adoptar los estándares de ruido del Capítulo 4, Anexo 16 al Convenio sobre la Aviación civil Internacional en junio de 2001 y posteriormente en la A33 a la llamada "aproximación equilibrada" que permite mayor autonomía en el criterio de definición de ruido a los Estados miembros. Aún pendientes de la decisión del TJE el Consejo dio la bienvenida a estos cambios en la OACI en su reunión 2374 y se propuso en el año 2002 la Directiva 30/2002 "sobre el establecimiento de normas y procedimientos para la introducción de restricciones operativas relacionadas con el ruido en los aeropuertos comunitarios", que concuerda con las novedades legislativas de la OACI. En última instancia, la acción unilateral de la UE tuvo el efecto de modificar el marco legislativo de la OACI sobre el control del ruido de los aviones.

\section{IMPACTO POTENCIAL EN EL SECTOR TURISMO}

En la relación entre turismo, aviación y gases de efecto invernadero hay dos puntos principales a considerar. El primero es el tamaño de la industria de turismo. El turismo es una las mayores industrias globales: "(...) el ingreso total de exportaciones generadas por el turismo recibido, incluido el transporte de pasajeros, superó los 1,2 billones de dólares americanos en 2011, o lo que es lo mismo, 3,4 millones de dólares americanos al día de promedio. Las exportaciones relacionadas con el turismo representan el $30 \%$ de las exportaciones mundiales de servicios comerciales y el $6 \%$ de las exportaciones totales de bienes y servicios. A nivel mundial, en la categoría de exportaciones, el turismo ocupa el cuarto lugar de volumen después de los combustibles, los productos químicos y los alimentos" (UNWTO, 2012). Desde que la aviación comenzara sus actividades comerciales ha establecido una relación simbiótica con el turismo. El turismo significa conectividad y gran parte de esa conectividad proviene de la industria de la aviación comercial. Este cambio en el sector turístico muestra un doble efecto. Por un 
lado, la industria del turismo contribuye al efecto invernadero. Por otro, muchas de las principales zonas turísticas del mundo se encuentran en las zonas potencialmente con mayor riesgo de exposición a las consecuencias del calentamiento global. Consecuentemente, la OMT tiene al cambio climático como una de sus mayores preocupaciones. Y muy especialmente en lo que atañe a la industria de la aviación comercial, está intentado encontrar un punto de equilibrio entre ambas caras de la moneda: "A nivel mundial, la OMT está trabajando junto con la OACI y con otros organismos de la industria - notablemente la WTTC y la AITA - con el objetivo de aumentar la coordinación entre el transporte aéreo y el turismo. El método consiste en posicionar el transporte aéreo y el turismo como un conjunto, como una industria estratégica, como un núcleo interconectado, que hable con una sola voz en cuestiones como la liberalización, la seguridad y asesoramiento en general, el cambio climático, los problemas relacionados con los temas de impacto económico y fiscal" (UNWTO, 2012).

Figura 4. Llegadas de turistas internacionales 2015

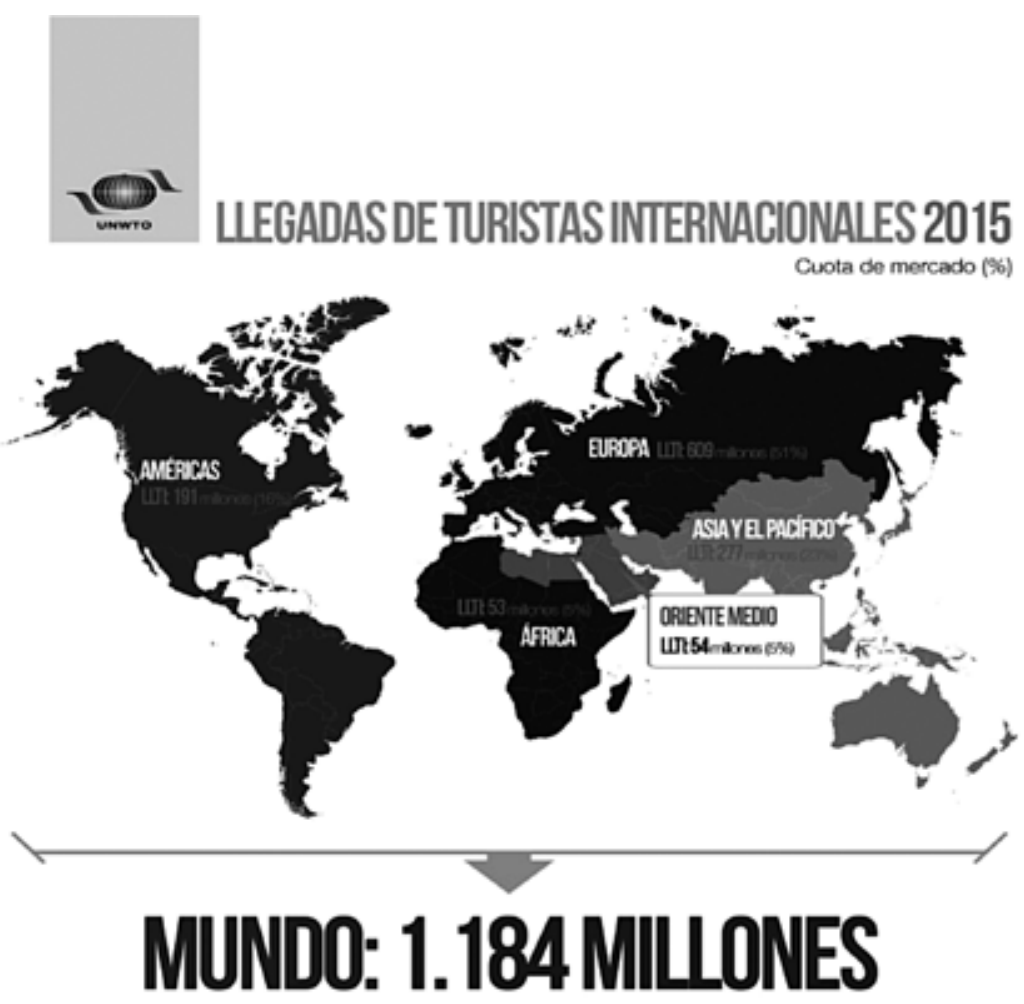

Fuente: OMT, 2016. 
El segundo factor a tener en cuenta es el crecimiento de la industria del turismo. Como se ha explicado en apartados previos, el remarcable crecimiento hasta la fecha, así como las proyecciones a futuro de las emisiones provenientes de industria de la aviación comercial han sido la principal causa de motivación para la regulación unilateral europea. El número de turistas no deja de aumentar. Así en fecha enero 2016 la OMT nos explica que "las llegadas de turistas internacionales aumentaron un 4,4\% en 2015 hasta alcanzar un total de 1.184 millones, según el último Barómetro del Turismo Mundial de la OMT. En comparación con 2014, el año pasado hubo alrededor de 50 millones más de turistas internacionales (visitantes que pernoctan) en todo el mundo" (OMT, 2016).

De este ingente número de turistas que se desplazan, la mayoría utilizan los medios aéreos como forma de transporte. Tomando de ejemplo un país eminentemente turístico como es España, se observa que según las últimas cifras oficiales publicadas en junio de 2015 por el Ministerio de Industria, Energía y turismo, el $79,7 \%$ de los turistas que llegaron a España utilizaron como vía de acceso los aeropuertos, a gran distancia de la segunda vía de acceso, la carretera, que solo supone un 18,4\% de los accesos (Subdirección Gral. de Estudios, Análisis y Planes de Actuación del Ministerio de Industria, Energía y Turismo del Reino de España-SGEAPA, 2015).

Figura 5. Llegadas de turistas internacionales: vías de acceso

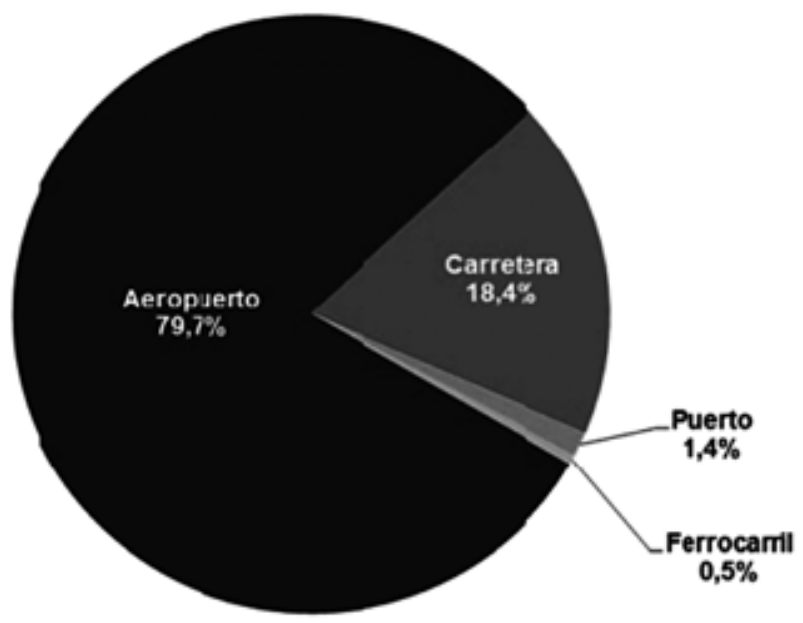

Fuente: SGEAPA, 2015.

Más transporte aéreo significa mayor volumen y superiores costes en adquirir derechos de emisión de gases de efecto invernadero. ¿Cómo se verá su estructura 


\section{F. Javier Heredia Yzquierdo y Antonio Sánchez-Bayón}

de costes afectada? Los operadores aéreos tendrán que afrontar costes operativos adicionales. Sin embargo, el impacto de estos costes depende de varios factores: dependerá de su eficacia en la gestión del combustible, de su eficacia operativa y sobre todo, de hasta qué punto son capaces de trasladar ese coste al usuario final, al viajero. Aquí se entra en una dinámica de competencia general en el libre mercado, ya que ante la disyuntiva de encarecer los precios para compensar este sobrecoste, cada operador tomará decisiones ejecutivas según sus propias políticas, situación en sus balances, planes de crecimiento a medio y largo plazo, momento económico y de consumo y otros factores que entiendan sean de consideración. Algunos estudios cifran el coste del impacto de estas medidas en los precios de los billetes aéreos y en la demanda que tendrán esos billetes. Las estimaciones que se barajan oscilan entre una subida de un euro a seis euros con sesenta céntimos de media en los billetes de vuelos de corta distancia. Para los billetes de vuelos de media distancia, se calcula una subida de entre un euro y ochenta céntimos y nueve euros. Para los billetes de larga distancia, entre ocho y cuarenta euros. Se puede pues argumentar que la posible subida de precios debida al factor emisiones de $\mathrm{CO}_{2}$ está quedando absorbida por la rebaja de combustibles. La propia Comisión Europea, encuentra que el impacto en los precios de las líneas aéreas es solo marginal y no está motivando que las líneas aéreas ni los pasajeros elijan otros aeropuertos extracomunitarios. La Comisión encuentra que el número de permisos que se necesitan para una ruta en concreto se encuentra ajustado en proporción dentro de las diferentes opciones en comparación con el marco general del RCED. El coste medio de los derechos de emisiones se integra como una marca más en el precio del combustible ${ }^{29}$. La Comisión encuentra igualmente que el coste en el precio de los billetes está siendo mínimo, de entre 0.1 y $1,1 \%$ en clase turista ${ }^{30}$.

\section{CONCLUSIONES}

En la actualidad, sigue sin haber un régimen político-jurídico común para un mercado global de derechos de emisiones. Cierto es que existen iniciativas como la de la OACI, pero aún por implementar de manera sostenible. Lo más próximo en tal sentido es el modelo de la UE, el cual ha suscitado un buen número de controversias, y sus polémicas aún no están resueltas.

La globalización, como proceso de interconexión (gracias a las tecnologías de la información y comunicación-TIC, Sánchez-Bayón, 2012 y 13), ha supuesto un

${ }^{29}$ Estudio de Impacto de la Comisión Europea (16 octubre 2013), p. 27 (URL: http://ec.europa.eu/ clima/policies/transport/aviation/docs/swd_2013_430_en.pdf; consultado 1/1/16, trad. propia).

${ }^{30}$ Estudio de Impacto de la Comisión Europea (16 octubre 2013), p. 28 (URL: http://ec.europa.eu/ clima/policies/transport/aviation/docs/swd_2013_430_en.pdf; consultado 1/1/16, trad. propia). 
remarcable aumento en la relevancia de la industria de la aviación comercial al transferirse la tecnología militar a la sociedad civil y liberalizarse los pasillos aéreos: un mundo globalizado es un mundo conectado y la industria de la aviación comercial permite viajar largas distancia, ya sea por negocios o por turismo. Su importancia va en aumento, y al tratarse de un sector de alcance global requiere de un foro internacional de entendimiento. La OACI ha sido este foro desde su creación en 1944, acogiendo propuestas de múltiples sujetos y actores internacionales; sin embargo, la multitud de interés, a menudo contrapuestos, ha dificultado la adopción de compromisos firmes, vinculantes y generalizados. Con todo, la OACI supone un ámbito de decisiones para un sector específico pero con alcance mundial. En el caso del control de emisiones de GEIs, las principales decisiones en tal sentido han quedado pospuestas a finales del año 2016, como fecha más cercana.

En cuanto al turismo, igualmente, está relacionado con el concepto de conectividad -tal como se viene planteando-. La aviación comercial también está creciendo en importancia al llevar a los turistas a diferentes partes del mundo. Si los precios del transporte suben para los viajeros, se corre el riesgo de que toda la industria del turismo, la cuarta de importancia a nivel mundial, sufra las consecuencias, ralentizándose en un marco económico que en muchas partes aún parece sombrío (tras la crisis financiera de 2008). Por el momento, este hecho no se ha producido debido a la disminución en los precios del combustible y la congelación de las políticas regulatorias sobre las emisiones por parte de la industria comercial aérea.

Es esta industria, regulada por la OACI, la que lleva consigo un problema creciente: las previsiones muestran que las emisiones de la industria de la aviación comercial tendrán un fuerte despunte. El mundo se enfrenta a un emisor de gases de efecto invernadero no regulado bajo el Protocolo de Kioto o bajo cualquier otro acuerdo internacional. Las compañías comerciales aéreas no tienen que compensar sus crecientes emisiones a través de ninguna compra de derechos de emisión de otros sectores. Por su lado, la UE ya tenía un programa de compraventa de derechos de emisiones general con el objetivo de cumplir con sus obligaciones bajo el Protocolo de Kioto y sus propios estrictos objetivos en materia medioambiental. Era por tanto un paso lógico que la Comisión Europea sumara esos factores y tomara la decisión unilateral que incluyera a este sector no regulado dentro del marco general. Sin embargo, en un mundo cada vez más globalizado también hay otros Estados de importancia que vieran en esta decisión un hecho que afecta a sus intereses nacionales. En un mundo civilizado, este tipo de controversias encuentran su cauce en el poder Judicial. Así, el TJUE consideró correcta la inclusión de la aviación comercial en el marco general de los mecanismos de control europeos. Esto llevó a una reacción por parte de algunos de los principales actores en la escena internacional: EE. UU., China y la India no muestran conformidad 
con la regulación europea de sus líneas aéreas comerciales. Especialmente al ver esa política refrendada por el TJUE. La situación se encuentra en la actualidad en suspenso, pues desde la UE se es consciente de que no se encuentra sola en el mundo, no deseándose una previsible situación de escalada hasta las cotas de una "guerra comercial". Actualmente la UE prefiere dar tiempo para hallar una situación internacional dentro de las Asambleas de la OACI, confiando en que el hecho de que un ente del peso de la UE haya amagado con una solución unilateral, así como la creciente conciencia general sobre el cambio climático, aumentará la presión en la A39 de la OACI en el otoño-invierno de 2016. Por el momento, los mecanismos de control de las emisiones de la industria de la aviación comercial a través del programa europeo de compraventa de derechos de emisión sólo se aplican para vuelos internos de la UE. Se está dando pues tiempo para que la OACI camina en esa dirección, la de crear un primer régimen mundial global para un sector específico. Esta estrategia, como se ve por el caso Hush-kit ya ha tenido éxito con anterioridad, satisfaciéndose en última instancia las expectativas de la UE.

\section{BIBLIOGRAFÍA}

\section{Obras doctrinales}

ANDERSON, K, et al. (2006), "Growth scenarios for EU \& UK Aviation: Contradictions with Climate Policy", Tyndall Center (research paper 84). BARKER, T., et al. (2007), "Technical Summary", en VV. AA., Mitigation. Contribution of Working Group III to the Fourth Assessment Report of the Intergovernmental Panel on Climate Change, Cambridge University Press, Cambridge.

FABER, J. y BRINKE, L. (2011), The Inclusion of Aviation in the EU ETS to: Economic and Environmental Consequences, ICTDS.

GRAICHEN, J. y GUGELE, B. (2006), Greenhouse Gas Emissions from Aviation, ETC/ACC Technical Paper.

KNORR A. y ARNDT A. (2012), The EU's Hushkit Regulation- Environmental Protection or Eco-protectionism, Univ. Bremen, Bremen.

LEGGETT J. A., et al. (2012), Aviation and the European Union emission trading scheme, Congressional Research Service.

METZ, B, y otros (2007), Climate Change, Cambridge University Press, Cambridge.

PAULINE, T. (2014), International Implementation of EU Emission Trading Scheme Still Unsettled, Holland \& Knight.

SÁNCHEZ-BAYÓN, A. (2011), Introducción al Derecho Comparado y Global, Delta, Madrid. 
SÁNCHEZ-BAYÓN, A. (2012), Humanismo Iberoamericano, Cara Parens, Guatemala.

SÁNCHEZ-BAYÓN, A. (2012), Sistema de Derecho Comparado y Global, Tirant Lo Blanch, Valencia.

SÁNCHEZ-BAYÓN, A. (2013), Renovación de la Filosofía Social Iberoamericana, Tirant Lo Blanch, Valencia.

SÁNCHEZ-BAYÓN, A. (2014), "Fundamentos de Derecho Comparado y Global", Boletín Mexicano de Derecho Comparado, núm. 141.

VERKI, M., et al. (2012), Legal analysis on the inclusion of civil aviation in the European Union emissions trading system, CISDL.

VV.AA. (2016), European Aviation Environmental Report-2016, Comisión Europea, Bruselas.

VV.AA. (2015), Informe anual 2014, SGEAPA, Madrid.

\section{Recursos electrónicos}

Airportwatch, "More problems for aviation in the EU" (URL: http://www. airportwatch.org.uk/2014/01/more-problems-for-aviation-in-the-eu-etsas-france-and-germany-will-not-enforce-sanctions-for-non-compliance/; consultado $1 / 1 / 16$, traducción propia).

AITA, "Fuel Price Analysis. Current price of aviation jet fuel" (URL: http:// www. AITA.org/publications/economics/fuel-monitor/pages/price-analysis.aspx; https://www. AITA.org/pressroom/Documents/AITA-letter-austria-chancellor-nov2010.pdf; consultado 1/1/16, traducción propia).

Comisión Europea, "European Aviation Environmental Report-2016" (URL: http://ec.europa.eu/transport/themes/strategies/doc/2011_white_paper/ white-paper-illustrated-brochure_es.pdf; http://ec.europa.eu/transport/ modes/air/international_aviation/country_index/united_states_en.htm; consultado $1 / 1 / 16$, trad. propia).

EPA, "US GHG Inventory Report, 2015" (URL: http://www.epa.gov/climatechange/Downloads/ghgemissions/US-GHG-Inventory-2011-Complete_Report.pdf; consultado 1/1/16, trad. propia).

Indexmundi, "Commodities Jet-Fuel" (URL: http://www.indexmundi.com/ commodities/?commodity=jet-fuel; consultado $1 / 1 / 16$, trad. propia).

MAGRAMA, "Comercio de derechos de emisión" (URL: http://www. magrama.gob.es/es/cambio-climatico/temas/comercio-de-derechos-deemision/14julio_asignacion_OOAA_2013-16_tcm7-338953.pdf; consultado $1 / 1 / 16$, trad. propia).

OACI, "Assembly Resolutions in force" (URL: http://www. OACI.int/Meetings/a38/Pages/ES/default_ES.aspx; http:/www.icao.int/environmentalprotection/Documents/A36_Res22.pdf; consultado 1/1/16, trad. propia). 
The Guardian (version online, URL: http://www.theguardian.com/environment/2013/jun/04/airlines-agree-to-curb-greenhouse-gas-emissions; consultado $1 / 1 / 16$, trad. propia).

TJUE, "Nota de prensa. no 104/11. 6 octubre 2011" (URL: http://curia.europa.eu/jcms/upload/docs/application/pdf/2011-10/cp110104es.pdf; consultado $1 / 1 / 16$, trad. propia).

UE, "Guidance Document (July 2012) The Monitoring and Reporting Regulation - General guidance for Aircraft Operators" (URL:

http://ec.europa.eu/clima/policies/ets/monitoring/docs/gd2_guidance_aircraft_en.pdf; consultado 1/1/16, trad. propia).

Transportenvironment, "Documents" (URL: http://www.transportenvironment.org/road-paris-climate-deal-must-include-aviation-and-shipping; consultado $1 / 1 / 16$, trad. propia).

UNFCC, "Copenhagen documents" (URL: http://unfccc.int/meetings/copenhagen_dec_2009/items/5264.php; consultado 1/1/16, trad. propia).

UNWTO, "Global Report on Aviation, 2012" (URL: http://www.everis.com/ global/WCLibraryRepository/References/tourism_study.pdf; consultado $1 / 1 / 16$, trad. propia 